\title{
Pre-school manager training: a cost-effective tool to promote nutrition- and health-related practice improvements in the Irish full-day-care pre-school setting
}

\author{
Charlotte Johnston Molloy ${ }^{1}{ }^{*}$, John Kearney ${ }^{2}$, Nóirín Hayes ${ }^{3}$, Corina Glennon Slattery ${ }^{1}$ \\ and Clare Corish ${ }^{2}$ \\ ${ }^{1}$ Community Nutrition and Dietetic Service, Health Service Executive Dublin Mid-Leinster, Primary Care Unit, \\ St. Loman's Hospital Campus, Co. Westmeath, Republic of Ireland: ${ }^{2}$ School of Biological Sciences, Dublin \\ Institute of Technology, Dublin, Republic of Ireland: ${ }^{3}$ Faculty of Applied Arts, Dublin Institute of Technology, \\ Dublin, Republic of Ireland
}

Submitted 13 December 2012: Final revision received 25 August 2013: Accepted 4 September 2013: First published online 18 0ctober 2013

\begin{abstract}
Objective: To evaluate the impact on nutrition- and health-related practice of two methods of delivery of a nutrition and health intervention in Irish full-day-care pre-schools: training of pre-school managers only or training of managers and their staff.

Design: A simple randomised study with pre-schools divided into two training groups: 'manager trained' and 'manager and staff trained'. Direct observational data - food and fluid provision, physical activity, outdoor time, staff practices and availability of nutrition and health resources - were recorded during one full day spent in each pre-school both pre- and post-intervention, using a specifically developed and validated Pre-school Health Promotion Activity Scored Evaluation Form. Post-intervention, self-assessment data were also collected using the same evaluation tool.

Setting: Pre-schools, Midlands of Ireland.

Subjects: A convenience sample of forty-two pre-schools registered with the Irish Health Service Executive.

Results: From pre- to post-intervention, significant improvement $(P<0 \cdot 05)$ in nutrition- and health-related practice was observed within both intervention delivery groups in all areas evaluated: environment, food service, meals and snacks. No additional effect attributable to staff training was observed. Scores assigned by direct independent observation were lower than pre-school self-assessment scores.

Conclusions: The implementation of a training intervention in pre-schools significantly improved practice with no significant benefit of additional staff training. Direct independent observation is required to quantify practice accurately.
\end{abstract}

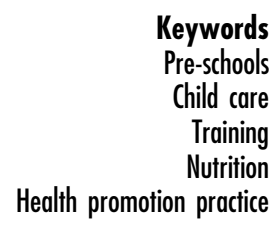

The provision of a physical and social environment that supports the pre-school child's physical growth and his/her emotional, intellectual and motor skill development is extremely important ${ }^{(1)}$. It has been noted that the child-care setting has the potential to be a successful vehicle for obesity prevention ${ }^{(2,3)}$ and for health promotion $^{(4)}$ and researchers have called for studies that will provide an understanding of nutrition and physical activity practices in pre-schools ${ }^{(5)}$. Kaphingst and Story ${ }^{(3)}$ suggest that although much intervention research has been undertaken in other settings, the child-care setting has been mostly overlooked. Flynn et $a l^{(6)}$, in reviewing best practice in reducing obesity and related chronic disease in children and young people, noted that funding should be directed to develop prevention programmes in this setting.

Many parents now rely on child-care providers to monitor their children's nutrient intake ${ }^{(7)}$. The education of children, in full day care, in the development of healthy eating patterns is becoming predominantly that of the child-care provider, the professionals charged with the care of children ${ }^{(8)}$. The promotion of physical activity through the development of motor skills is very important too during the pre-school years; however, little research is available for this population ${ }^{(9)}$. Therefore, paediatricians and health-care professionals have a role in highlighting to parents and caregivers the importance of nurturing these skills through unstructured and structured play ${ }^{(10)}$. 
Although guidelines are available in a number of jurisdictions regarding the promotion of best nutrition, physical activity and health practice for the early years setting ${ }^{(11-17)}$, associated regulations have been noted to be poor ${ }^{(3,18,19)}$, with the environment of the child-care facility instead evaluated mainly for safety ${ }^{(20,21)}$.

In Ireland, the pre-school is a relatively new setting with the number of children attending for full day care increasing rapidly in recent years ${ }^{(22)}$; currently, there is no uniform formal training for pre-school staff on nutrition and healthy food or physical activity provision, nor does the legislation enforce such training to exist. Irish 'Food and Nutrition Guidelines for Pre-school Services ${ }^{,(14)}$ and physical activity guidelines ${ }^{(23)}$ are available but are not mandatory, which would suggest that methods to encourage the provision of nutritious foods and physical activity in this setting must be pursued.

To this end, in the Midlands of Ireland, a multi-stakeholder 'Local Expert Group' which included community dietitians, a pre-school inspector, a training officer, a child-minding advisory officer and a pre-school services manager developed an intervention scheme (the Healthy Incentive for Pre-schools Project). A 'National Advisory Committee' was then established to support the project, and comprised relevant experts from a range of national agencies (safefood, Early Childhood Ireland, the Health Service Executive, Healthy Food for All, Dublin Institute of Technology). The aim of the project was to develop a validated nutrition- and health-related evaluation tool for pre-schools, the Pre-school Health Promotion Activity Scored Evaluation Form, and to determine whether use of this evaluation tool supported by delivery of a specifically developed Pre-school Nutrition and Health Education Resource could promote improved food service and nutrition and physical activity practices in the full-day-care pre-school setting.

Prior to administration of the Pre-school Health Promotion Activity Scored Evaluation Form in the present study, its validity was determined through a number of recommended phases ${ }^{(20,24-26)}$ : a comprehensive review of the literature to establish face and content validity; the development and definition of 'best practice criterion standards' to enable assessment of practice at three levels 'not minimum standard' (0 points), 'minimum standard' (1 point) and 'best practice' ( 3 points); its review by the 'National Advisory Committee' and 'Local Expert Group' to determine construct validity and to establish reliability; the development of a detailed form to collect observational data and establish criterion validity (Pre-school Detailed Assessment Tool); and the development of a form to collect relevant data on the characteristics of each pre-school (Pre-school Characteristic Collection Form) ${ }^{(27)}$.

The structure of the validated Pre-school Health Promotion Activity Scored Evaluation Form comprised four sections; each section contained six separate questions or criteria relating to best practice (Table 1). Section scores
Table 1 Pre-school Health Promotion Activity Scored Evaluation Form sections and criteria

\begin{tabular}{|c|c|}
\hline Sections & Criteria \\
\hline Environment & $\begin{array}{l}\text { Whole pre-school health policy } \\
\text { Education-related activities } \\
\text { Planned physical activity } \\
\text { Outside playtime } \\
\text { Evidence of food use as reward/treat } \\
\text { Appropriate number of meals and snacks }\end{array}$ \\
\hline Food service & $\begin{array}{l}\text { Staff sitting with children at food times } \\
\text { Staff eating same food as children at food times } \\
\text { Practice of 'family-style food service' } \\
\text { Adequate allocation of time for food times } \\
\text { Adequate encouragement and appropriate } \\
\text { self-feeding } \\
\text { Age-appropriate feeding and drinking utensil use }\end{array}$ \\
\hline Meals & $\begin{array}{l}\text { Appropriate serving of protein at main meal } \\
\text { Appropriate serving of starch at main meal } \\
\text { Appropriate serving of dairy at main meal } \\
\text { Appropriate serving of vegetables at main meal } \\
\text { Meals offered in self-service style } \\
\text { Fe-rich food provision at main meal }\end{array}$ \\
\hline Snacks & $\begin{array}{l}\text { Fruit at least once other than main meal } \\
\text { Foods offered from top shelf of the Food Pyramid } \\
\text { Dairy food at least once other than main meal } \\
\text { Tap water and milk only with snacks } \\
\text { Tap water, milk or appropriately diluted juice } \\
\text { with meals } \\
\text { Tap water or milk offered between meals } \\
\text { and snacks }\end{array}$ \\
\hline
\end{tabular}

were obtained by adding all criteria scores in each relevant section. Addition of the four section scores provided the overall score. Each pre-school was classified into a category by its overall score: participation (score 0-19), bronze (score 20-39), silver (score 40-54), gold (score 55-64) or platinum (score 65-72).

The Pre-school Nutrition and Health Education Resource was specifically developed for the present study and included two booklets: a 'Best Practice Guide', which outlined the Pre-school Health Promotion Activity Scored Evaluation Form, the best practice criterion standards' and the steps needed to use these to achieve best practice; and the 'Hints and Tips Pack', which provided relevant in-depth best practice information from the literature in a user-friendly format and whose content is linked to, and signposted from, the Best Practice Guide'. Testing of the Pre-school Nutrition and Health Education Resource was undertaken with the 'Local Expert Group' and with child-minders prior to its use in the study.

The present study tests the hypothesis that, in comparison to pre-schools receiving an intervention comprising 'manager only' training, those pre-schools randomised to receive a staff education session in addition to manager training would have greater improvements from preto post-intervention in nutrition and physical activity practices and food service provision, when measured using a specifically developed and validated Pre-school Health Promotion Activity Scored Evaluation Form. 


\section{Methods}

\section{Pre-study pilot}

In preparation for the present study, a pilot study ${ }^{(27)}$ was undertaken in twelve pre-schools in a geographical area similar to the Midlands of Ireland (County Wicklow) to test the tools designed for the project: the Pre-school Health Promotion Activity Scored Evaluation Form, the Pre-school Detailed Assessment Tool and the Pre-school Characteristic Collection Form.

\section{Study setting}

This simple, randomised, parallel-group study took place in forty-two pre-schools offering a 'full day care service' across four midland counties of the Republic of Ireland from March 2008 to April 2012. Pre-schools included in the study were situated in towns, villages and the countryside in a geographical area defined as disadvantaged ${ }^{(28)}$. A 'full day care service' is defined in Ireland as 'a pre-school service offering a structured day care service for pre-school children for more than $5 \mathrm{~h} / \mathrm{d}^{,(21)}$.

\section{Study participants}

Convenience sampling was undertaken. An up-to-date list of pre-schools ( $n$ 100) providing a 'full day care service' (i.e. for more than $5 \mathrm{~h} / \mathrm{d})^{(21)}$ was obtained from the Health Service Executive in the midland region of Ireland. Excluded were pre-schools that provided only sessional (less than $3.5 \mathrm{~h} /$ session $^{(21)}$ ) or part-time care for children; pre-schools designated as ineligible by the Pre-school Inspection Team due to insufficient standard in other pre-defined areas of inspection; and pre-schools that had not been inspected by the Pre-school Inspection Team in the previous 12-month period. Pre-schools were invited to participate and seventy-six registered their interest; of these, fourteen pre-schools did not proceed to the pre-intervention data collection phase due to: change in service provision type, i.e. full day care to sessional care service provision ( $n$ 9); exclusion by the Pre-school Inspection Team ( $n$ 4); and service closure $(n 1)$. The study was conducted according to the guidelines laid down in the Declaration of Helsinki and all procedures involving human subjects were approved by the Research Ethics Committee of the Health Service Executive Dublin MidLeinster, Ireland and the Ethics Committee of the Dublin Institute of Technology, Ireland. Written informed consent was obtained prior to pre-intervention data collection from all pre-school managers participating in the project.

\section{Healtby Incentive for Pre-schools Project intervention}

A random-number table was used to allocate pre-schools into two parallel intervention training groups: a group in which only the manager of each pre-school was trained ('manager trained' group; $n$ 30) and a group in which the manager was trained and, in addition, the staff were also trained ('manager and staff trained' group; $n$ 31); one pre-school had closed prior to randomisation occurring.

Contact by telephone was made with each pre-school manager and an appointment made to provide feedback to them solely ('manager trained' group) or to give feedback to them as the manager and, in addition, to organise a staff training session ('manager and staff trained' group). Appointments and training sessions were confirmed in writing.

Prior to the intervention, specific detailed A4 'written feedback records' for each pre-school were generated by the research dietitian, through review of each preschool's pre-intervention data collection file. The records generated followed the format of the Pre-school Health Promotion Activity Scored Evaluation Form. The observations made during the pre-intervention visit which related to each criterion, and the score this observed practice had attained, were outlined. Practical methods to improve and attain a best practice score in each criterion were also included in the written information.

\section{'Manager trained' group intervention}

The research dietitian met face to face with each preschool manager individually for a $1 \mathrm{~h}$ training session. During this period, the research dietitian first outlined the project process to date, the next project steps and the resources available. Second, the Pre-school Nutrition and Health Education Resource was introduced to each manager, and each best practice criterion on the Pre-school Health Promotion Activity Scored Evaluation Form was outlined and discussed. Third, each manager was provided with his/her individualised 'written feedback record' from the pre-intervention visit. Each observation on this record was discussed with the manager as were the suggested strategies for improvement that were outlined. Sufficient numbers of the Pre-school Nutrition and Health Education Resource were provided to each manager for distribution of one copy to each staff member.

Feedback was undertaken with twenty-seven of the 'manager trained' group; reasons for non-participation included: inability to contact the pre-school manager $(n 1)$; service provision not appropriate $(n 1)$; and closure of service $(n 1)$.

\section{'Manager and staff trained' group intervention}

The manager training in this group mirrored that provided to managers in the 'manager trained' group. In addition, in each of the pre-schools, a structured staff education session, of $1.5 \mathrm{~h}$ duration, was undertaken by the research dietitian.

The adult learning methodologies of group work and group discussion were employed to structure the staff education sessions. Each session included presentation of a number of topics using an informal table-top A1 presentation device. Each topic presentation was followed with group work exercises for the participants. Each group work session culminated in an overall group 
discussion facilitated by the research dietitian. The presentation topics were the Pre-school Health Promotion Activity Scored Evaluation Form and use of the Pre-school Nutrition and Health Education Resource to achieve best practice; determination of adequate meal and snack composition; healthy foods and fluids for pre-school children; establishing appropriate serving size provision for pre-school children; the 'family-style food service' concept; and healthy pre-school policy development.

Training and feedback were arranged with eighteen of thirty-one of the 'manager and staff trained' group services. There were a number of factors that led to the reduction in this training group: four services could not be contacted; one declined to participate, citing a change in its circumstances; one provided a service that was not appropriate, having changed from offering full day care to offering only sessional service; and one had closed its service. Furthermore, a number of pre-schools randomised to the 'manager and staff trained' group had difficulties in facilitating training for staff, thus preventing participation in the training process. Postal feedback was instead sent to these pre-schools ( $n$ 6). Although post-intervention data were collected from these six pre-schools, following discussion with the 'National Advisory Group', this group was omitted from paired data analysis of the effectiveness of the intervention.

\section{Data collection methods}

All pre-schools with a 'full day care service' in the Midlands were allocated a code for the duration of the project. Pre- and post-intervention data were collected by the one research dietitian using the specifically designed evaluation tools.

Each service was contacted by telephone at least two weeks in advance to arrange a convenient time and date to visit; written confirmation of visit details was subsequently sent to each service. Each pre-school visit began approximately $45 \mathrm{~min}$ to $1 \mathrm{~h}$ before the first food service time in that pre-school to enable collection of detailed pre-school characteristics from each pre-school manager using the specifically designed Pre-school Characteristic Collection Form. Visits to pre-schools were arranged for each day of the week (Monday to Friday), with data collected by the researcher during one full day, both preand post-intervention, in each individual pre-school.

In the course of each pre-school visit, each meal and snack time was observed. This involved spending time in the kitchen before the meal/snack time to determine the food serving size of the food being plated if this was the practice in the service. A description of all foods offered was recorded using household measures. A photographic food atlas developed specifically for the Healthy Incentive for Preschools Project, using food serving sizes recommended for pre-school children ${ }^{(14,29)}$ and recipes from the Irish Health Service Executive '3-week menu plan - a resource for preschools $^{,(30)}$, were used to aid data collection ${ }^{(31)}$. Practice was observed in each room of the service, regarding: the foods and fluids served; the meal time experience for children; staff/child interaction during the food time; and the room environment. Physical activity participation and outdoor clothing and time provision were observed and recorded.

All observations were detailed on the Pre-school Detailed Assessment Tool. Criterion scores on the Preschool Health Promotion Activity Scored Evaluation Form were assigned during each pre-school visit by comparing the observations collected on the Pre-school Detailed Assessment Tool to the project's 'best practice criterion standards'. The score for each section, as well as the overall score, were calculated and the overall score used to classify each pre-school into a category of participation, bronze, silver, gold or platinum.

Post-intervention, in addition to the research dietitian's observation-based data collection, pre-school managers were requested to observe and self-report their own practice using the Pre-school Health Promotion Activity Scored Evaluation Form, returning their self-assessment within one week of the observation visit to the research dietitian, to enable comparison between their self-assessment scores and the direct observation scores assigned.

\section{Statistical analyses}

Data were analysed using the statistical software package IBM SPSS Statistics Version 20. Analyses of intervention outcomes included pre-schools that completed all phases of the project: the training intervention and the pre- and post-intervention data collection phases ( $n$ 42). Normality of distribution was assessed using the Kolmogorov-Smirnov statistic and distribution of normal probability plots. Nonparametric statistical data analysis was undertaken as data were measured on nominal and ordinal scales, were not transformed and sample size was relatively small. The Wilcoxon signed-rank test was used to test for differences in Pre-school Health Promotion Activity Scored Evaluation Form scores within each intervention group across two time points, pre- and post-intervention; while the Mann-Whitney $U$ test was used to test differences between the two intervention groups at the pre-intervention and post-intervention time points. Results were considered significant at $P<0 \cdot 05$.

\section{Results}

\section{Pre-school characteristics}

Pre-intervention data were collected in sixty-two preschools: private $(n 42)$ and community, not for profit $(n 20)$ with data from four services excluded from analysis (consent not provided ( $n$ 2); service for intellectual disabilities $(n 1)$;

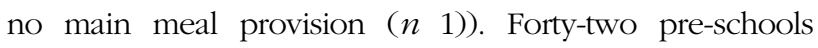
(twenty-six private, sixteen community) completed both the intervention and post-intervention phases of the project. Figure 1 outlines the progress of eligible pre-schools through the project process. 


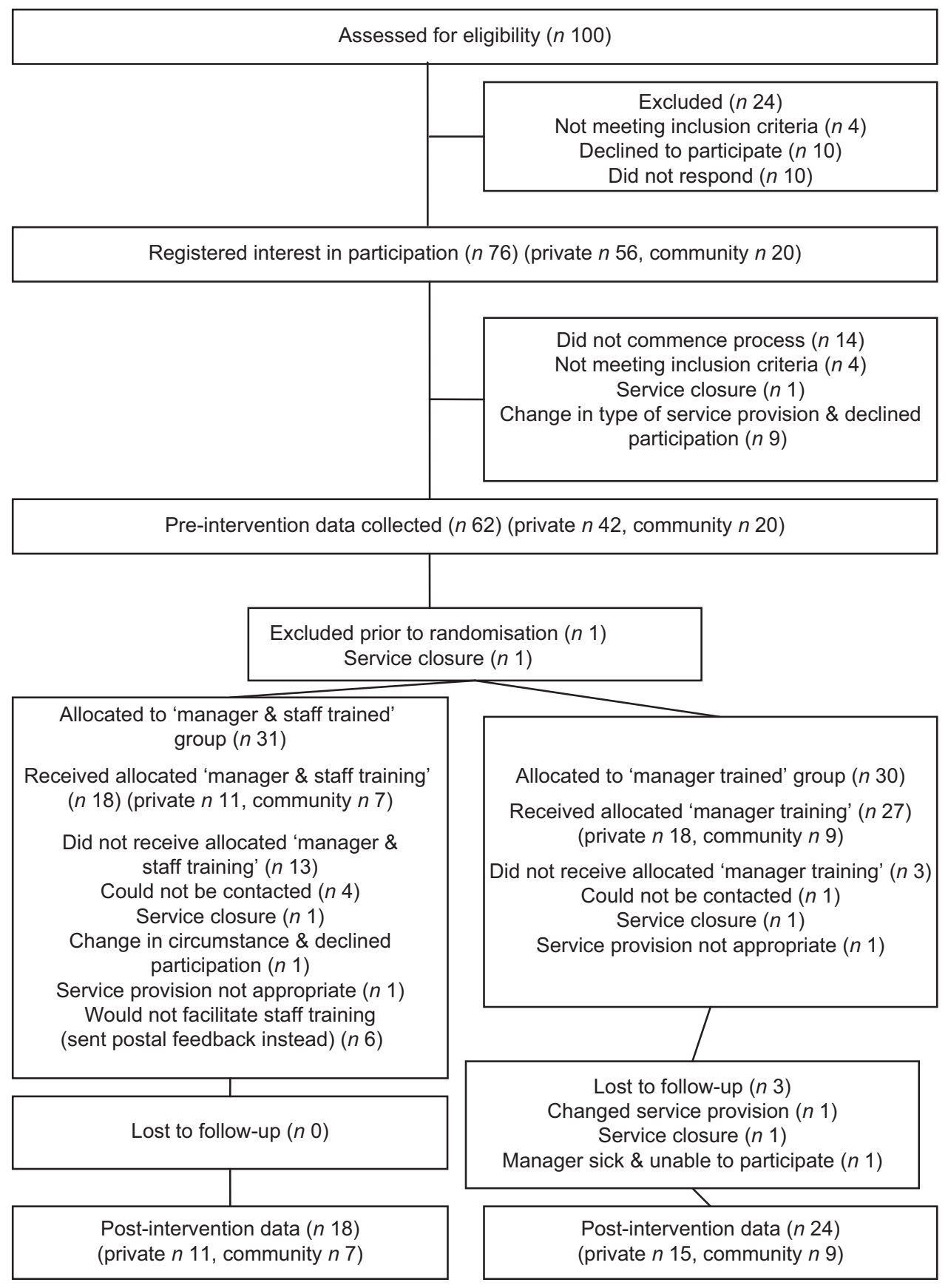

Fig. 1 Flow diagram showing the progress of pre-schools through the randomised parallel-group study

Table 2 outlines the pre-intervention characteristics of all pre-schools; those that proceeded to the post-intervention phase of the project and those that did not. No statistically significant difference was noted between the characteristics of these two sets of preschools.

\section{Pre-intervention criteria scores achieved by pre-schools}

No significant difference in pre-intervention evaluation scoring was detected between the pre-schools that proceeded to the post-intervention phase and those that did not. Table 3 outlines the section and overall scores achieved by these two groups pre-intervention.

\section{Pre-school Health Promotion Activity Scored Evaluation Form scores}

Table 4 outlines the median Pre-school Health Promotion Activity Scored Evaluation Form section and overall scores and their respective interquartile ranges, across two time points, pre- and post intervention, in both intervention delivery groups. 
Significant improvements in health promotion practices occurred across the two time points in both training groups. Pre-intervention, no significant differences were noted between the 'manager trained' and 'manager and staff trained' groups in any evaluation score, nor were any significant differences in practice detected between the two groups post-intervention. The majority of pre-schools in both groups moved into higher project classification categories (bronze and silver) post-intervention.

\section{Pre-school Health Promotion Activity Scored Evaluation Form scoring methods}

Table 5 depicts the scores allocated by direct observation and by reported self-assessment within the two intervention delivery groups. Higher evaluation scores were attained through subjective (self) assessment when compared with objective (research dietitian) assessment.

\section{Discussion}

The present intervention study is the first of its kind to take place in pre-schools offering a 'full day care' service in Ireland. It provides insight into nutrition- and healthrelated practice in this setting and into the outcomes derived from providing two methods of training delivery to the pre-schools studied.

Many experts have stated that child-care providers must provide suitable nutrition and an environment that fosters healthy habit formation ${ }^{(16,32)}$. The findings of the current research would suggest that fears about the quality and quantity of food served in this setting ${ }^{(33)}$ are justified, with pre-intervention data showing: inadequate food and fluid provision; an inappropriate food service environment to promote healthy habit formation; and an environment that was not conducive to nutrition education or participation in physical activity and outdoor time. Although sixteen of the fifty-eight pre-schools visited during the pre-intervention phase did not proceed to the post-intervention phase of the project, their characteristics and scoring were similar to those of the forty-two preschools that did progress, indicating that bias towards poorer practice among pre-schools that did not proceed is unlikely.

Although international research demonstrates inadequate food provision ${ }^{(34-36)}$ and food service ${ }^{(37,38)}$ in the child-care setting, in Ireland little is known about the food provided to children in child care other than that reported by pre-school managers themselves ${ }^{(39)}$. While the findings of the National Pre-school Nutrition Survey ${ }^{(40)}$ demonstrate poor intakes of vitamin A, Fe and the risk of vitamin D deficiency among children of pre-school age, these data are for a general population, cared for both in the home and in out-of-home care and, to date, no data are available from this survey specifically relating to the intakes of children in full-time care in Ireland ${ }^{(40)}$. 
Table 3 Pre-intervention Pre-school Health Promotion Activity Scored Evaluation Form section scores and overall scores, Republic of Ireland, March 2008-April 2012

\begin{tabular}{|c|c|c|c|c|c|}
\hline & \multicolumn{2}{|c|}{$\begin{array}{l}\text { Pre-schools which progressed to } \\
\text { post-intervention phase } \\
\qquad(n 42)\end{array}$} & \multicolumn{2}{|c|}{$\begin{array}{l}\text { Pre-schools which participated } \\
\text { in pre-intervention phase only } \\
\qquad(n 16)\end{array}$} & \multirow[b]{2}{*}{$P$ value } \\
\hline & Median & IQR & Median & IQR & \\
\hline \multicolumn{6}{|c|}{ Section scores (maximum 18 each) } \\
\hline Environment & 3 & $2-4$ & 3 & $2-4$ & $0 \cdot 872$ \\
\hline Food service & 2 & $1-3$ & 2 & $1-4$ & 0.691 \\
\hline Meals & 4 & $2-5$ & 4 & $2-7$ & 0.634 \\
\hline Snacks & 6 & $4-9$ & 4 & $3-6$ & 0.089 \\
\hline Overall score (maximum 72) & 14 & $12-20$ & 16 & $10-19$ & 0.780 \\
\hline
\end{tabular}

IQR, interquartile range.

Table 4 Pre-school Health Promotion Activity Scored Evaluation Form section scores and overall scores pre- and post-intervention in the two intervention groups, Republic of Ireland, March 2008-April 2012

\begin{tabular}{|c|c|c|c|c|c|c|c|c|c|c|c|}
\hline & \multicolumn{4}{|c|}{$\begin{array}{l}\text { 'Manager trained' } \\
\text { group ( } n \text { 24) }\end{array}$} & \multirow[b]{3}{*}{$P$ valuet } & \multicolumn{4}{|c|}{$\begin{array}{l}\text { 'Manager and staff trained' } \\
\text { group }(n 18)\end{array}$} & \multirow[b]{3}{*}{$P$ valuet } & \multirow[b]{3}{*}{$P$ value: } \\
\hline & \multicolumn{2}{|c|}{ Pre-intervention } & \multicolumn{2}{|c|}{ Post-intervention } & & \multicolumn{2}{|c|}{ Pre-intervention } & \multicolumn{2}{|c|}{ Post-intervention } & & \\
\hline & Median & IQR & Median & IQR & & Median & IQR & Median & IQR & & \\
\hline \multicolumn{12}{|c|}{ Section scores (maximum 18 each) } \\
\hline Environment & 3 & $2-4$ & 8 & $4-10$ & $<0.001^{\star \star *}$ & 3 & $3-4$ & 8 & $5-10$ & $<0.001^{\star \star *}$ & 0.626 \\
\hline Food service & 2 & $1-3$ & 6 & $4-11$ & $<0.001^{\star \star \star}$ & 2 & $1-4$ & 6 & $4-7$ & $0.004^{\star \star}$ & 0.608 \\
\hline Meals & 4 & $2-5$ & 8 & $4-10$ & $0 \cdot 001^{\star \star}$ & 4 & $3-5$ & 9 & $6-13$ & $0 \cdot 001^{\star *}$ & 0.207 \\
\hline Snacks & 5 & $4-9$ & 12 & $8-16$ & $<0 \cdot 001^{\star \star *}$ & 7 & $5-9$ & 11 & $10-12$ & $0 \cdot 001^{\star \star}$ & 0.565 \\
\hline Overall score (maximum 72) & 13 & $11-21$ & 34 & $21-45$ & $<0 \cdot 001^{* \star *}$ & 15 & $14-19$ & 34 & $27-41$ & $<0.001^{\star \star *}$ & $0 \cdot 849$ \\
\hline
\end{tabular}

IQR, interquartile range.

${ }^{\star} P<0.05,{ }^{\star \star} P<0.01,{ }^{\star \star *} P<0.001$.

+Wilcoxon signed-rank test.

¥Mann-Whitney $U$ test.

Table 5 Post-intervention Pre-school Health Promotion Activity Scored Evaluation Form section scores and overall scores in the two intervention groups according to allocation method (observation and self-assessment), Republic of Ireland, March $2008-$ April 2012

\begin{tabular}{|c|c|c|c|c|c|c|c|c|c|c|}
\hline & \multicolumn{4}{|c|}{ 'Manager trained' group } & \multirow[b]{3}{*}{$P$ valuet } & \multicolumn{4}{|c|}{ 'Manager and staff trained' group } & \multirow[b]{3}{*}{$P$ valuet } \\
\hline & \multicolumn{2}{|c|}{$\begin{array}{l}\text { Observation } \\
\quad(n 24)\end{array}$} & \multicolumn{2}{|c|}{$\begin{array}{l}\text { Self-assessment } \\
(n 16)\end{array}$} & & \multicolumn{2}{|c|}{$\begin{array}{l}\text { Observation } \\
(n 18)\end{array}$} & \multicolumn{2}{|c|}{$\begin{array}{l}\text { Self-assessment } \\
(n 11)\end{array}$} & \\
\hline & Median & IQR & Median & IQR & & Median & IQR & Median & IQR & \\
\hline \multicolumn{11}{|c|}{ Section scores (maximum 18 each) } \\
\hline Environment & 8 & $4-10$ & 16 & $14-16$ & $0 \cdot 000^{* * *}$ & 8 & $5-10$ & 16 & $10-18$ & $0 \cdot 003^{\star *}$ \\
\hline Food service & 7 & $4-11$ & 15 & $12-18$ & $0 \cdot 001^{\star \star \star}$ & 6 & $4-7$ & 16 & $11-18$ & $0 \cdot 003^{\star \star}$ \\
\hline Meals & 8 & $4-10$ & 16 & $15-18$ & $0 \cdot 000^{\star * *}$ & 9 & $6-13$ & 16 & $14-18$ & $0 \cdot 010^{\star}$ \\
\hline Snacks & 12 & $8-16$ & 16 & $16-18$ & $0 \cdot 001^{\star \star *}$ & 11 & $10-12$ & 16 & $13-18$ & $0.026^{*}$ \\
\hline Overall score (maximum 72) & 34 & $21-45$ & 64 & $57-67$ & $0 \cdot 000^{\star \star *}$ & 34 & $27-41$ & 64 & $56-66$ & $0.003^{\star *}$ \\
\hline
\end{tabular}

${ }^{*} P<0.05,{ }^{* *} P<0.01,{ }^{* * *} P<0.001$.

tWilcoxon signed-rank test.

As adequate energy and nutrients are essential for normal growth and development in infancy and child$\operatorname{hood}^{(6,14,29,41,42)}$, the pre-intervention results of the present study suggest that children attending full-day-care services in Ireland may be at risk of nutrient deficiencies, such as $\mathrm{Fe}$ and $\mathrm{Ca}$, due to inadequate food provision. The foods provided in a child's first two years of life influence the foods eaten in later life ${ }^{(43)}$ while nutrition and physical activity habits $^{(44-46)}$ also appear to track into adolescence and adulthood. Given the results of the present study, children in Irish full-day-care pre-school services may be missing the development of healthy associations with food and physical activity, thus risking inappropriate habit development.

Although many experts have stated that child-care providers must provide suitable nutrition and an environment 
that fosters healthy habit formation ${ }^{(16,32)}$, the findings of the current research would suggest that, pre-intervention, fears that have been expressed in other countries ${ }^{(33)}$ regarding the quality and quantity of food served may also be justified in Ireland where, to date, the statutory regulations governing pre-school nutrition and physical activity lack detail ${ }^{(21)}$. Importantly, the American Dietetic Association warns that while child-care regulations represent minimum standards, there is a danger that some might aim for these only, rather than striving to achieve best practice ${ }^{(47)}$. It is necessary, therefore, that pre-school managers and health professionals working with preschools encourage services and their staff to prioritise health-related habit formation among children due the long-reaching effects that these habits have ${ }^{(45,46,48)}$. While a study in the USA found that child-care policy may have a positive effect on promoting some healthy carer behaviours at meal times, policy alone may not be sufficient to promote staff to consume healthy food with children when children are eating ${ }^{(49)}$. The Healthy Incentive for Pre-schools Project encourages policy development; however, this is but one element of an overall package aiming to empower pre-schools to become health promoting with the encouragement, for instance, of 'familystyle food service', another example of best practice essential to the overall matrix.

The use of the Pre-school Health Promotion Activity Scored Evaluation Form and its associated classification system, supported by education, acted as a motivational tool for pre-school services. Significant improvements in overall practices were observed with the majority moving from a 'participation' classification pre-intervention to a higher classification post-intervention. The education provided detailed specific actions for pre-schools to follow, which were in the form of criterion standards for best practice, bringing clarity to the task of determining what changes are required and how these can be implemented.

With direct observation being described as a 'gold standard ${ }^{(50)}$, the findings in the present study confirm that a significant difference existed between the scores assigned by the direct observation method in comparison to those conferred by self-assessment, with the latter scoring being significantly more generous.

While a number of initiatives ${ }^{(51,52)}$ have in the past relied on self-assessment of practice, the limitation of such methodology has been acknowledged ${ }^{(8)}$. The results of the present study confirm the need to interpret any findings based on self-assessment with caution. However, as it was not possible to test inter-rater reliability in our study, the difference in scoring achieved through selfassessment could be attributed to pre-school staff's inability to use the Pre-school Health Promotion Activity Scored Evaluation Form as a measurement tool rather than due to 'optimistic bias' on their part. The findings of the study may, in fact, inform the direction of funding away from 'whole staff training' and towards the need for independent observation, to ensure validity of results obtained, as part of an overall initiative to encourage quality practice. In fact, a concern about quality in childcare provision has led to the development of quality improvement initiatives aimed at improving standards above the minimum, with enhanced funding for better providers ${ }^{(53)}$, and more state child-care financing to serve children from low-income or at-risk backgrounds ${ }^{(54)}$. The motivational aspect of the classification system in the Healthy Incentive for Pre-schools Project is similar to that outlined by Sisson et $a l .{ }^{(55)}$ who determined that the star rating of child-care centres leads to differences in best practice levels, with centres conferred with a three-star rating reporting higher frequency of such best practice standards, when compared with services with a lower star rating.

The current results indicate that pre-school manager training is as effective in eliciting change in nutrition- and health-related practice as the provision of a more resource-intensive staff training model. The randomisation of the pre-schools into two training groups, one group receiving a resource-intensive intervention comprising staff training in addition to manager education, and the second group receiving an intervention requiring significantly fewer resources and entailing training the manager of the pre-school only, enabled analysis of whether staff training conferred any additional benefit on the outcomes measured. Contrary to expectation, the provision of staff training did not have a significant effect on the overall outcomes measured. Perhaps this finding is related to the training of staff in this setting or it may be linked to the positive impact of leadership on quality practice in the early years' setting ${ }^{56,57)}$. This result, however, is beneficial, particularly in the current economic environment in which resources are scarce. Given the added cost to the health service of providing staff training and the difficulties in releasing staff for training from the pre-schools' perspective, the finding that 'manager only' training can deliver results equivalent to a more intensive intervention is welcome, both from the viewpoint of pre-schools and the health service; a point of further research here would be to establish why this might be the case.

Potentially, there are a number of limitations to the present study that must be acknowledged. First, rather than using the traditional method of dividing a study into two arms, control and intervention, in essence the current research involved two levels of intervention. The decision to follow this study format was for a number of reasons: to ensure maintenance of pre-school engagement in the project process; because 'true control group' contamination prevention would have been unfeasible in this setting; and because ethically it was determined that to ensure best child welfare, all pre-schools in the study should receive an intervention. The study results may also 
be limited by the fact that the data were collected in each service on one day only, pre- and post-intervention, and therefore may not be seen to fully reflect the practices of an individual pre-school on a weekly or monthly basis. However, as pre-schools were assessed on different days of the week to determine an aggregate picture of practice, we are confident that the routines reported do reflect normal practice within the study pre-schools.

To heighten reliability, all observations were also made by one research dietitian, ensuring consistency of assessment across the forty-two pre-schools observed. Although this in itself may be considered a limitation, as it was not possible to determine inter-rater reliability, having even one extra 'outside' person in a pre-school setting may affect the inherent practice undertaken by staff and therefore one researcher would cause minimal interruption compared with the effect of a team of researchers working in a single setting on a particular day. Minimal disruption to staff and children is an important consideration when planning any research activity in this setting. Observation, considered the most effective data collection method $^{(50)}$, by one individual helped to ensure quality data were obtained despite the aforementioned limitations.

It could also be said that making an appointment to visit each pre-school both pre- and post-intervention essentially 'prepared' pre-schools to alter practice for the visit of the researcher and that this is a possible limitation. However, to counteract this possibility, pre-schools were not advised pre-intervention of the specific components that would be observed on the visit day. Further, postintervention, pre-schools had by then been trained and so were aware of the standards expected, thus potentially impacting on results achieved. However, the practice observed could be said to reflect actual routines and habits as, by the very nature of pre-schools and the children cared for therein, it would be difficult to alter an everyday child-care approach within a two-week period, as practices undertaken with this age group require much repetition and time to change ${ }^{(58,59)}$.

Although the number of pre-schools that completed all phases of the study may be regarded as small, it is important to note that the population of full-day-care pre-schools in the Midlands of Ireland is finite. A good representation of community and privately owned services, with a wide geographical spread, was obtained despite the economic recession which evolved during the project process that caused closure and movement of pre-schools from full day care to sessional care service and which had not been anticipated during the project planning process. While the study was based in a relatively rural disadvantaged setting in the Republic of Ireland, it is possible that the practices observed pre-intervention may be present in pre-schools in other areas. The beneficial learning from the present study could be applied to other pre-schools offering a 'full day care service', therefore providing the possibility of improving nutrition and health habits of a large number of children in full-time care.

\section{Conclusion}

The present intervention was the first in Irish pre-schools to directly observe nutrition- and health-related practices and demonstrate that introduction of a pre-school evaluation tool and an education resource for managers motivated improved practices with no significant additional effect noted with additional staff education. Direct independent observation was confirmed as the optimum method of assessment in this setting. Introduction of the Healthy Incentive for Pre-schools Project to other pre-schools offering a 'full day care service' in Ireland has the potential to encourage the implementation of best practice guidelines, thereby enhancing quality. Further testing of this project in other settings is warranted to determine whether such implementation could play an important role in the enhancement of pre-school environments and pre-school provider practice.

\section{Acknowledgements}

Sources of funding: This material is based upon works supported by safefood, the Food Safety Promotion Board (under safefood grant no. 01-2008); in association with the Health Service Executive, Ireland. Conflicts of interest: No authors of this research article have any conflicts of interest to report. Authors' contributions: C.J.M., J.K., N.H., C.G.S. and C.C. designed the study. C.J.M. carried out the fieldwork under direction from C.C., J.K., N.H. and C.G.S. C.J.M., C.C. and J.K. were involved in the interpretation of the findings. C.J.M. wrote the initial draft of the manuscript under the supervision of C.C. All authors critically reviewed the manuscript and contributed to, and agreed upon, the final version to be submitted for publication consideration. Acknowledgements: The authors would like to gratefully acknowledge all preschool services for their time and participation in this project process.

\section{References}

1. Dwyer JT (1993) Childhood, youth and old age. In Human Nutrition and Dietetics, 9th ed, pp. 394-408. [JS Garrow and WPT James, editors]. Edinburgh: Churchill Livingstone.

2. Story M, Kaphingst KM \& French S (2006) The role of child care settings in obesity prevention. Future Child 16, 143-168.

3. Kaphingst KM \& Story M (2009) Child care as an untapped setting for obesity prevention: state child care licensing regulations related to nutrition, physical activity, and media use for preschool-aged children in the United States. http://www.cdc.gov/pcd/issues/2009/jan/07_0240.htm (accessed September 2012). 
4. Gupta RS, Shuman S, Taveras EM et al. (2005) Opportunities for health promotion education in child care. Pediatrics 116, e499-e505.

5. Larson N, Ward D, Benjamin Neelon S et al. (2011) Preventing obesity among preschool children: how can child-care settings promote healthy eating and physical activity? http:// www.healthyeatingresearch.org/images/RS_ChildCare_For_ posting_on_web_FINAL_10-27-11.pdf (accessed September 2012).

6. Flynn MAT, McNeill DA, Maloff B et al. (2006) Reducing obesity and related chronic disease in children and youth: a synthesis of evidence with 'best practice' recommendations. Obes Rev 7, 7-66.

7. American Dietetic Association (2005) Position of the American Dietetic Association: benchmarks for nutrition programs in child care settings. J Am Diet Assoc 105, 979-986.

8. Lanigan JD (2012) The relationship between practices and child care providers' beliefs related to child feeding and obesity prevention. I Nutr Educ Behav 44, 521-529.

9. Hodges EA, Smith C, Tidwell S et al. (2013) Promoting physical activity in preschoolers to prevent obesity: a review of the literature. J Pediatr Nurs 28, 3-19.

10. Riethmuller AM, Jones RA \& Okely AD (2009) Efficacy of interventions to improve motor development in young children: a systematic review. Pediatrics 124, e782-e792.

11. Scottish Executive (2006) Nutritional Guidance for Early Years: Food Choices for Children Aged 1-5 Years in Early Education and Childcare Settings. Edinburgh: Scottish Executive.

12. Welsh Assembly Government (2009) Food and Health Guidelines for Early Years and Childcare Settings. Cardiff: Welsh Assembly Government.

13. Health Promotion Agency for Northern Ireland (2005) Nutrition Matters for The Early Years: Healthy Eating for the Under Fives in Childcare. Belfast: Health Promotion Agency for Northern Ireland.

14. Department of Health and Children (Ireland) (2004) Food and Nutrition Guidelines for Pre-school Services. Dublin: Health Promotion Unit.

15. Government of South Australia (2005) Eat Well SA Schools and Preschools: Healthy Eating Guidelines Implementation Tool. Developing a Whole School/Preschool Healthy Eating Policy. Adelaide: Department of Education and Children's Services \& Department of Health.

16. American Academy of Pediatrics \& American Public Health Association (2002) Caring for our Children, National Health and Safety Performance Standards: Guidelines for Out-ofHome Child Care. http://nrckids.org/CFOC/PDFVersion/ National $\% 20$ Health $\% 20$ and $\% 20$ Safety $\% 20$ Performance $\% 20$ Standards.pdf (accessed October 2009).

17. School Food Trust (2012) Eat Better Start Better: Voluntary Food and Drink Guidelines for Early Years Settings in England - A Practical Guide. London: Children's Food Trust/School Food Trust.

18. Benjamin SE, Copeland KA, Cradock A et al. (2009) Menus in child care: a comparison of state regulations with national standards. J Am Diet Assoc 109, 109-115.

19. Benjamin SE, Taveras EM, Cradock AL et al. (2009) State and regional variation in regulations related to feeding infants in child care. Pediatrics 124, 104-111.

20. Ammerman AS, Ward DS, Benjamin SE et al. (2007) An intervention to promote healthy weight: Nutrition and Physical Activity Self-Assessment for Child Care (NAP SACC) theory and design. Prev Chronic Dis 4, A67.

21. Department of Health and Children (Ireland) (2006) Child care (pre-school services) (No 2) regulations 2006 and explanatory guide to requirements and procedures for notification and inspection. http://www.dohc.ie/publications/ childcaresi20060604.html (accessed February 2011).
22. Central Statistics Office (Ireland) (2009) Quarterly National Household Survey: Childcare: quarter 4. http://www. cso.ie/releasespublications/documents/labour_market/2007/ childcareq42007.pdf (accessed February 2011).

23. Department of Health (Ireland) \& Health Service Executive (2011) Fact sheet for childcare providers. http://www. getirelandactive.ie (accessed September 2011).

24. Alkon A, To K, Wolff M et al. (2008) Assessing health and safety in early care and education programs: development of the CCHP health and safety checklist. J Pediatr Health Care 22, 368-377.

25. Benjamin SE, Neelon B, Ball SC et al. (2007) Reliability and validity of a nutrition and physical activity environmental self-assessment for child care. Int J Behav Nutr Phys Act 4, 29.

26. Falbe J, Kenney EL, Henderson KE et al. (2011) The Wellness Child Care Assessment Tool: a measure to assess the quality of written nutrition and physical activity policies. J Am Diet Assoc 111, 1852-1860.

27. Johnston Molloy C, Corish C, Kearney J et al. (2011) Developing a nutrition assessment tool for Irish preschools. Nutr Food Sci $\mathbf{4 1}, 44-53$.

28. Small Area Health Research Unit (2006) The SAHRU National Deprivation Index. http://www.sahru.tcd.ie/services/ deprivation.php (accessed November 2009).

29. Crawley H (2006) Eating Well for Under-5s in Child Care: Practical and Nutritional Guidelines. St Austell: The Caroline Walker Trust.

30. Irish Health Service Executive (2004) 3-Week Menu Plan: A Resource for Pre-Schools. Dublin: Health Service Executive.

31. Johnston Molloy C, Corish C, Kearney J et al (2010) Letters to the Editor. J Hum Nutr Diet 23, 426-427.

32. Bristow K, Capewell S, Abba K et al. (2011) Healthy eating in early years settings: a review of current national to local guidance for North West England. Public Health Nutr 14, 1008-1016.

33. Briley M \& McAllaster M (2011) Nutrition and the child-care setting. J Am Diet Assoc 111, 1298-1300.

34. Padget A \& Briley ME (2005) Dietary Intakes at child-care centers in central Texas fail to meet Food Guide Pyramid recommendations. J Am Diet Assoc 105, 790-793.

35. Ball SC, Benjamin SE, Dunne S et al. (2008) Dietary intakes in North Carolina child-care centers: are children meeting current recommendations? I Am Diet Assoc 108, 718-721.

36. Erinosho T, Dixon LB, Young C et al. (2011) Nutrition practices and children's dietary intakes at 40 child-care centers in New York city. J Am Diet Assoc 111, 1391-1397.

37. Hendy HM (2002) Effectiveness of trained peer models to encourage food acceptance in preschool children. Appetite 39, 217-225.

38. Nahikian-Nelms M (1997) Influential factors of caregiver behavior at mealtime: a study of 24 child-care programs. J Am Diet Assoc 97, 505-509.

39. Jennings A, McEvoy S \& Corish C (2011) Nutritional practices in full-day-care pre-schools. J Hum Nutr Diet 24, 245-259.

40. Irish Universities Nutrition Alliance (2012) National Preschool Nutrition Survey. Summary report. http://www. iuna.net (accessed July 2012).

41. Food Safety Authority of Ireland (1999) Recommendations for a National Infant Feeding Policy. Dublin: Food Safety Authority of Ireland.

42. Lozoff B, Jimenez E, Hagen J et al. (2000) Poorer behavioral and developmental outcome more than 10 years after treatment for iron deficiency in infancy. Pediatrics 105, E51.

43. Skinner JD, Carruth BR, Bounds W et al. (2002) Do foodrelated experiences in the first 2 years of life predict dietary variety in school-aged children? J Nutr Educ Behav 34, 310-315. 
44. Singer MR, Moore LL, Garrahie EJ et al. (1995) The tracking of nutrient intake in young children: the Framingham Children's Study. Am J Public Health 85, 1673-1677.

45. teVelde S, Twisk JWR \& Brug J (2007) Tracking of fruit and vegetables consumption from adolescence into adulthood and its longitudinal association with overweight. Br J Nutr 98, 431-438.

46. Telama R (2009) Tracking of physical activity from childhood to adulthood: a review. Obes Facts 2, 187-195.

47. American Dietetic Association (2011) Position of the American Dietetic Association: benchmarks for nutrition in child care. J Am Diet Assoc 111, 607-615.

48. Batsell RW, Brown AS, Ansfield ME et al. (2002) You will eat all of that!: a retrospective analysis of forced consumption episodes. Appetite 38, 211-219.

49. Erinosho TO, Hales DP, McWilliams CP et al. (2012) Nutrition policies at child-care centers and impact on role modelling of healthy eating behaviors of caregivers. $J$ Acad Nutr Diet 112, 119-124.

50. Gittelsohn J, Shankar AV, Pokhrel RP et al. (1994) Accuracy of estimating food intake by observation. J Am Diet Assoc 94, 1273-1277.

51. Benjamin SE, Ammerman A, Sommers J et al. (2007) Nutrition and physical activity self-assessment for (NAP SACC): results from a child care pilot intervention. $J$ Nutr Educ Behav 39, 142-149.
52. Bravo A, Cass Y \& Tranter D (2008) Good food in family day care: improving nutrition and food safety in family day care. Nutr Diet 65, 47-55.

53. Mooney A (2007) The Effectiveness of Quality Improvement Programmes for Early Childhood Education and Childcare. London: Thomas Coram Research Unit and University of London.

54. Organisation for Economic Co-operation and Development (2006) Starting Strong II: Early Childhood Education and Care. Paris: Organisation for Economic Co-operation and Development.

55. Sisson SB, Campbell JE, May KB et al. (2012) Assessment of food, nutrition, and physical activity practices in Oklahoma child-care centers. J Acad Nutr Diet 112, 1230-1240.

56. Siraj-Blatchford I \& Manni L (2006) Effective Leadership in the Early Years Sector (ELEYS) Study. London: University of London.

57. Sylva K, Melhuish E, Sammons P et al. (2004) Effective PreSchool Education. London: Department for Education and Skills.

58. Cooke L (2007) The importance of exposure for healthy eating in childhood: a review. J Hum Nutr Diet 20, 294-301.

59. O'Connell ML, Henderson KE, Luedicke J et al. (2012) Repeated exposure in a natural setting: a preschool intervention to increase vegetable consumption. J Acad Nutr Diet 112, 230-234. 